\title{
Calculation of the Coseismic Landslide Volume Using DEMs: An Example from the Yingxiu Area, Wenchuan, Sichuan, China
}

\author{
Xiaoli Chen ${ }^{1},{ }^{1}$ Yijian Chuan, ${ }^{2}$ and Yankun Wei ${ }^{1}$ \\ ${ }^{1}$ Key Laboratory of Seismic and Volcanic Hazards China Earthquake Administration, Institute of Geology, \\ China Earthquake Administration, Beijing 100029, China \\ ${ }^{2}$ School of Mathematical Sciences, Peking University, Beijing 100871, China \\ Correspondence should be addressed to Xiaoli Chen; chenxl@ies.ac.cn
}

Received 10 October 2020; Revised 22 December 2020; Accepted 22 February 2021; Published 1 March 2021

Academic Editor: Jian Xu

Copyright (C) 2021 Xiaoli Chen et al. This is an open access article distributed under the Creative Commons Attribution License, which permits unrestricted use, distribution, and reproduction in any medium, provided the original work is properly cited.

Volume calculation is important for quantifying the erosion driven by coseismic landslides in geomorphology. With the advent of digital elevation models (DEMs), quantifying features of landslide bodies have become possible, permitting to calculate the landslide volume in terms of elevation changes. To further test this approach, this work calculates the volume of landslides near the epicenter of the $2008 \mathrm{Mw} 7.9$ Wenchuan earthquake in the Yingxiu region, Sichuan, China, by comparing pre- and postearthquake DEMs. Results suggest that effective application of this method needs to consider the DEM resolution and eliminates background errors of individual landslides. The volume of coseismic landslides calculated by the proposed method may represent a minimum value compared to that from the existing empirical $V-A$ formulas. Considering that it is difficult to quantify the coseismic landslide volume throughout in a broad region, this method can be applied to the preliminary stage of characterizing coseismic landslides quantitatively for some key localities of the affected area of major earthquakes.

\section{Introduction}

Frequency, area, and volume are three main parameters to measure seismically induced landslides. Determination of these parameters is important for geologic hazard assessment and examining the role of landslides in landscape evolution [1-6]. For example, by comparing the estimated coseismic landslide volume with the volume of material added to the orogen through coseismic rock uplift, Parker et al. argued that mass wasting triggered by the 2008 Wenchuan earthquake was greater than orogenic growth, leading to a net material deficit in the Longmenshan [6]. In general, the total number and area of landslides can be estimated based on aerial photography or remote sensing data, coupled with field investigations [7-11]. In contrast, estimating the landslide volume remains difficult because the depth of landslide bodies is typically unknown [10-12].

To solve this problem, researchers use a power-scaling relation between the volume and area to estimate the volume of individual landslides or total volume of multiple landslides. Such a relation is expressed as

$$
V=\alpha A^{\gamma}
$$

where $V$ is the volume of landslides, $A$ is the area of landslides, and $\alpha$ and $\gamma$ are coefficients. This relation was originally proposed by Simonett [12] which assumes that the volume of a landslide is positively correlated with its area, determined using regression analysis of morphometric data. This formula has been applied to many case studies $[5,6,13]$. However, variations in landslide distribution and size, which are influenced by environmental factors (e.g., tectonic setting, lithology, grain size, and slope), can create uncertainties in the result of this approach, especially for large-scale landslides [10, 13-17]. Sometimes, the landslide volume derived from the area-volume equation is much larger than that estimated based on the relation between the landslide volume and moment magnitude of the earthquake $[1,3,18]$.

Recently, high-resolution and multitemporal DEMs have proven valuable to identify patterns of landscape 
evolution with coseismic topographic changes [18-20]. It is possible to estimate the landslide volume in terms of elevation changes from DEMs before and after earthquakes. For example, in their study on the landslides triggered by the 2008 Wenchuan M7.9 earthquake, Xu et al. (2016) calculated volumes of 1,415 landslides based on differences between pre- and postearthquake DEMs with $20 \mathrm{~m}$ resolution. They proposed three optimized models to calculate volumes of these coseismic landslides, depending on multiple morphometric attributes (area, length, width, height etc.). Unfortunately, uncertainties remain a problem when calculating differences between DEMs, as they often are collected from various data sources [20]. Both pre- and postseismic DEMs contain elevation errors, so comparison of continuous GPS data is required to yield relatively accurate elevation data. Besides, the elevation error is not a constant, instead varying with locations [18], which makes it somewhat difficult using DEM data to measure the volume of landslides.

Here, we propose a method to more accurately calculate the volume of coseismic landslides by removing measurement error caused by differences in DEM resolution and other irregularities using pre- and postearthquake DEMs. The test of this approach is performed based on the data from the Yingxiu area, Sichuan, China, near the epicenter of the 2008 Mw 7.9 Wenchuan earthquake which triggered massive coseismic slope failures. We then compare calculated coseismic landslide volumes with the values from different area-volume relations. Finally, we discuss the advantages of this method and provide a linear relation between $\log (V)$ and $\log (A)$.

\section{Data and Methods}

2.1. Study Area. The $2008 \mathrm{Mw} 7.9$ Wenchuan earthquake triggered thousands of coseismic landslides over an expansive region [21]. The study area of this work is located near the epicenter of this earthquake covering $66 \mathrm{~km}^{2}$. This region has the highest density of coseismic landslides caused by the event $[7,21]$ and experienced a Modified Mercalli Intensity (MMI) of XI [22]. The exposed strata in the study area are mainly sourced from the Precambrian Pengguan massif [23]. Topographically, the area is featured by an approximately 2,350 meter deep canyon, where the Minjiang River and its two tributaries converge. The Wenchuan earthquake surface rupture zone passes through the southeastern border of the study area near the epicenter, and the majority of landslides resides within the hanging wall of the seismogenic fault (Figures 1(a) and 1(b)).

2.2. Data. Two DEMs from different sources are used in this study. The pre-earthquake DEM is downloaded from $30 \mathrm{~m}$ Shuttle Radar Topography Mission (SRTM) elevation data (http://srtm.csi.cgiar.org/SELECTION/inputCoord.asp).

The postearthquake DEM is derived from GF2 remote images after radiometric and orthophoto correction and panchromatic and multispectral fusion processing and has a spatial resolution of 10 meters.
Based on aerial photography (with a resolution of $2 \mathrm{~m}$ ) in June 2008, we manually interpret coseismic landslides in the study area following the criteria suggested by Dai et al., namely, (a) landslide deposits that can be clearly identified at the foot of the slope covering roads or other infrastructures or extending into rivers or streams; (b) landslides that show newly denuded vegetation on the slope; (c) landslides that show bright white or dark brown contrast to surrounding slopes; and (d) landslide debris movement paths that can be clearly observed [7]. Because it is difficult to make a distinction between the source area and deposit for most landslides on aerial photos, each mapped polygon includes both source and deposit areas. Also, some small landslides are considered as single landslides when they appear as partly merged. As a result, more than 304 landslides are mapped with areas ranging 1800 to over $160,000 \mathrm{~m}^{2}$. Although the study area is a very small part of the Wenchuan earthquake affected area, the relationship between the landslide area and frequency density, which is defined as the ratio between the landslide number within the corresponding landslide area class and the total number of landslides in the whole inventory, is consistent with that of Malamud et al. [3] and others [11, 24, 25] (Figure 1(c)).

2.3. Methods. Landsliding can change elevation of the affected area (Figure 2). In general, when subtracting the preearthquake DEM from the postearthquake DEM at a pixel of the grid model, the negative values and the positive values represent the elevation changes in the source region and the deposition region, respectively. Then, based on the pre- and postearthquake DEM data, the difference of elevation $(\Delta D)$ for each pixel can be calculated as

$$
\Delta D=\left(D_{\text {post }}-D_{\text {pre }}\right),
$$

where $D_{\text {pre }}$ and $D_{\text {post }}$ are elevations before and after the earthquake, respectively (Figure 2). Assuming each pixel represents a unit area $(A)$ in the DEM, the changes in volume driven by landsliding can be calculated using the following equation:

$$
V=\sum_{i=1}^{N} A \times \Delta D_{i}=A \times \sum_{i=1}^{N} \Delta D_{i},
$$

where $N$ is the number of pixels within a single landslide polygon, $A$ is the area of a pixel, and $\Delta D i$ is the elevation difference of $i$ th pixel. This equation means that the volume of a landslide can be calculated by DEM changes of all pixels within the landslide polygon.

In general, when interpreting landslides from remote imagery, both source and deposit areas are included in one polygon. Therefore, the mass of material evacuated from the source area should be equal to the mass gained in the deposition area (i.e., net gain is equal to net loss). Thus, when equation (2) is used, we see the result of $V=0$. As $A$ is a constant value of the DEM pixel area, the value of $V$ depends on $\sum \Delta D$. Within a landslide, $\sum \Delta D=0$ leads to $V=0$. Although some studies show the expansion rate of a landslide as about $20 \%$ in cohesive soil-mantled regions due 

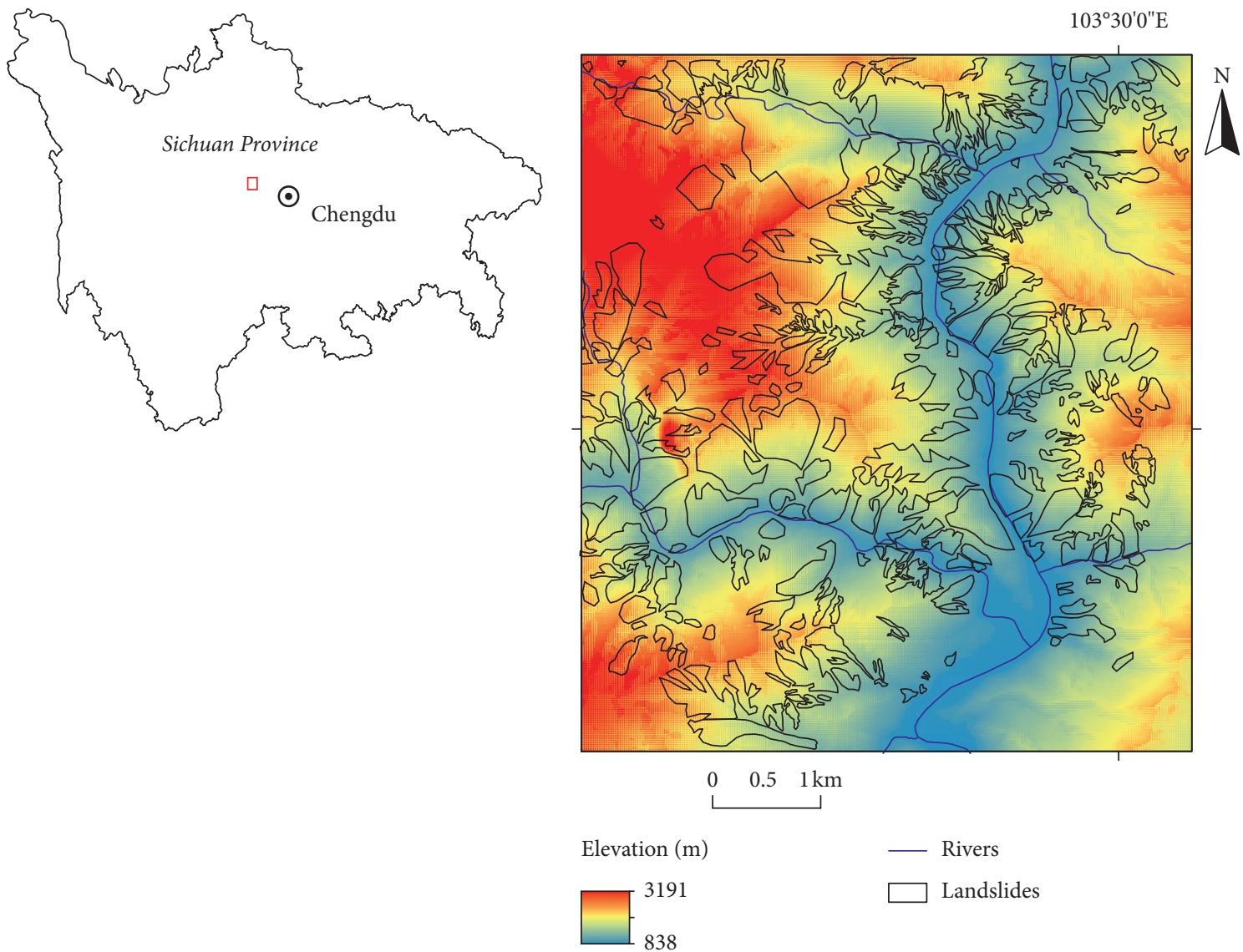

(a)

(b)

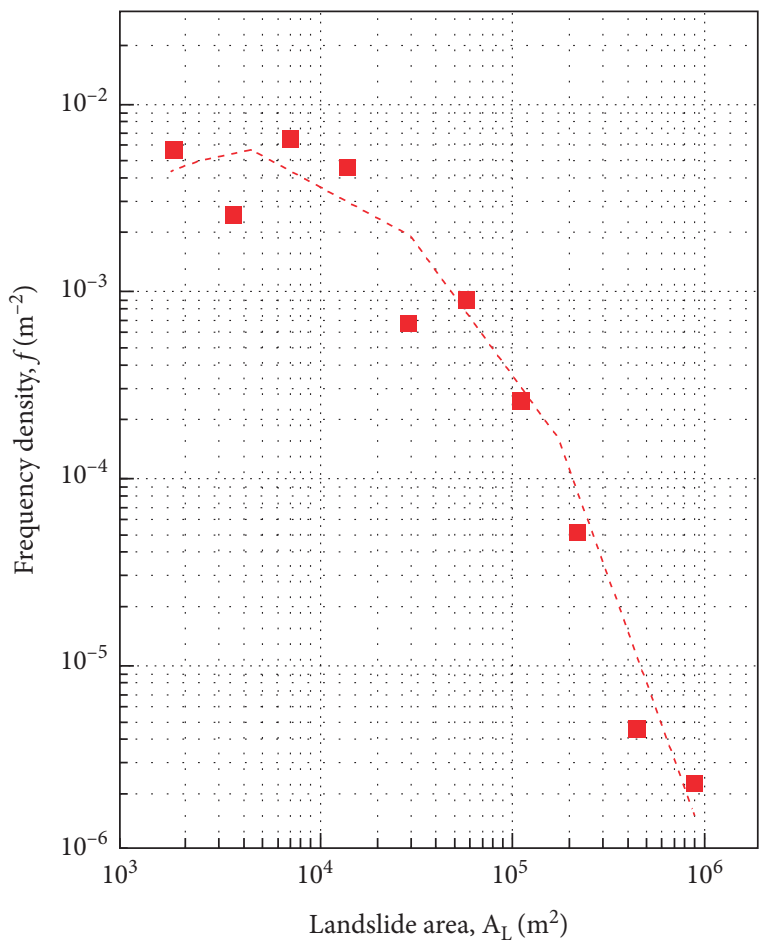

(c)

Figure 1: Geographic location of the study area and the coseismic landslides triggered by the 2008 Wenchuan earthquake. (a) Location of study area. (b) Shaded elevation map showing coseismic landslides in the study area. (c) Landslide area versus frequency density in the study area. 


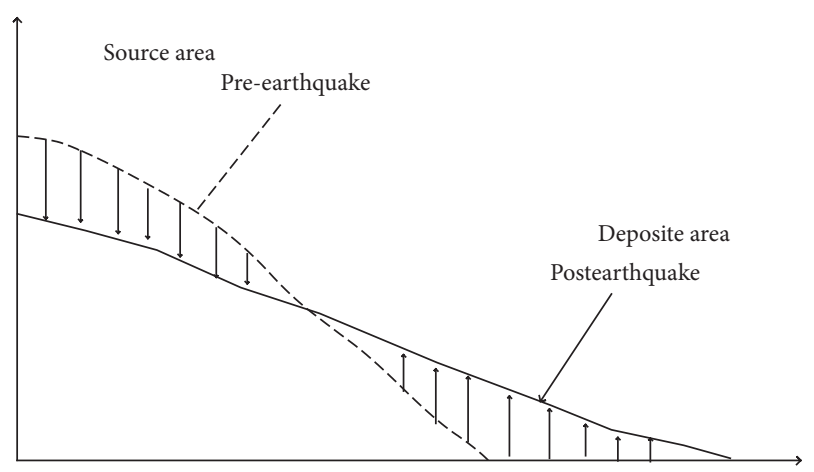

FIGURE 2: Sketch showing the elevation change of slope after seismic landsliding.

to long run-out distances $[26,27]$, we temporally neglect such mass expansion given that the study region is bedrockmantled by the Pengguan massif rather than sedimentary rocks.

Before the calculation of elevation changes, the preearthquake DEM, which has a resolution of $30 \mathrm{~m}$, is resized to the same resolution of $10 \mathrm{~m}$ similar to the postearthquake DEM. However, applying the DEM differential method faces a problem of background errors in data, mainly due to different DEM resolutions [10, 18-20, 28]. For example, when summing up $\Delta D$ using the number of pixels within the extent of a landslide, the value of $\sum \Delta D$ is always greater or less than zero. As shown in the map of coseismic elevation change, which is obtained by applying the cut-fill tool of ArcGIS, the topographic change is not consistent with the distribution of coseismic landslides (Figure 3). The errors here are obvious because most of the presented values are unreasonable in reality. For example, even in areas not impacted by landslides, the results still illustrate either net gain or net loss, implying the changes of elevation. This phenomenon differs from our assumptions, which should place this value near zero following the net loss from the source area which is equal to the net gain in the deposition area.

Based on the idea aforementioned, we use the following procedures to correct the errors in DEMs firstly and then calculate the landslide volume.

2.3.1. Calculating the Initial Difference between Pre- and Postearthquake DEMs. For a given landslide, the initial difference of elevation for each pixel, $\Delta D_{I}$, is defined as $\Delta D_{I}=\left(D_{\text {post }}-D_{\text {pre }}\right)$. Here, $\Delta D_{I} \geq 0$ represents the deposition area with net gain, while $\Delta D_{I}<0$ represents the source area with net loss (Figure 2). Due to systematic errors, $\sum \Delta D_{I}$ is always far from zero, displaying both greater than and less than zero values. In this case, it is assumed that this nonzero value $\sum \Delta D_{I}$ comes from all the pixels in the landslide.

2.3.2. Calculating the Background Error. In our assumption, for each landslide which includes both source and deposit areas, the net gain should be equal to the net loss when the DEMs are applied. Then, the error (i.e., $\sum \Delta D_{I}$ ) is evenly distributed among the pixels within a landslide and forms a background error: $\Delta D_{B}$. The following equation shows the procedure for calculating $\Delta D_{B}$ :

$$
\Delta D_{B}=\frac{\sum_{\text {within landslide }} \Delta D_{I}}{\text { number of pixels }}
$$

2.3.3. Calculating True Elevation Change. This means that the true elevation change for each pixel, namely, corrected difference $(\Delta D)$ between the pre- and postearthquake DEM, is obtained by calculating the background error $\left(\Delta D_{B}\right)$ and subtracting this value from the initial difference in elevation, $\Delta D_{I}$ (Equation (5)). Figure 4 shows the process and the comparison between landslide values containing the background error and after removal of this error.

$$
\Delta D=\Delta D_{I}-\Delta D_{B}
$$

2.3.4. Calculating the Landslide Volume. After correcting background errors, the mass removed from the source area of a landslide is equal to the mass accumulated in the deposition area. From the corrected data, a landslide volume can be calculated by summing all pixels with positive $\Delta D$ values within the landslide area and multiplying this value by the area of one pixel $\left(100 \mathrm{~m}^{2}\right)$ (represented by purple dots in Figure 4), as shown in the following equation:

$$
V=A \times \sum_{i=1}^{N} \Delta D_{i}\left(\Delta D_{i}>0\right)
$$

After calculation of volumes of all individual landslides, it is easy to obtain the volume of all landslides in the study area.

\section{Results}

Using the approach above, we calculate the volume of coseismic landslides in the study area. Figure 5(a) shows coseismic landslides with $\Delta D_{I}$ (before correction), and Figure 5(b) shows coseismic landslides with $\Delta D$ (after correction). Compared to Figure 5(a), results of Figure 5(b) are reasonable because they show that each landslide satisfies equation $\quad V=\sum$ within landslide $A \times \Delta D=\sum$ $A \times \Delta D(\Delta D>0)+\sum A \times \Delta D(\Delta D<0)=0$, namely, in a landslide, the mass moved from the source area is equal to the mass gained in the deposit area. It should be noted that, in Figure 5(b), as the same background error is subtracted by each pixel, it is not the reflection of real landslides (e.g., there are some net gain pixels appearing in the net loss areas).

Finally, the volume of coseismic landslides in the study area is calculated to be $1.765 \times 10^{8} \mathrm{~m}^{3}$.

In addition, based on the calculated volume and known area of individual landslides, this work uses equation (7) to perform a regression analysis:

$$
\log (V)=\log (a)+b \log (A)+\varepsilon .
$$




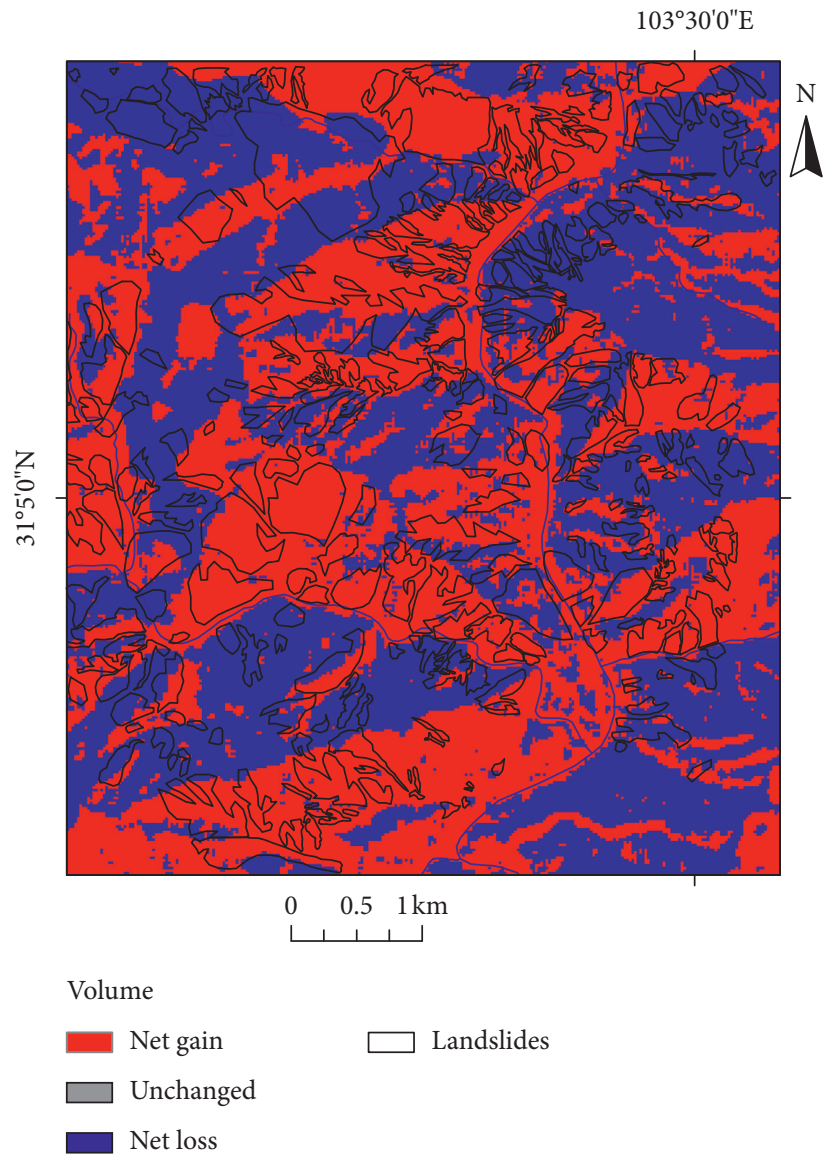

Figure 3: Net gain and net loss in the study area obtained by using the cut-fill tool of ArcGIS.

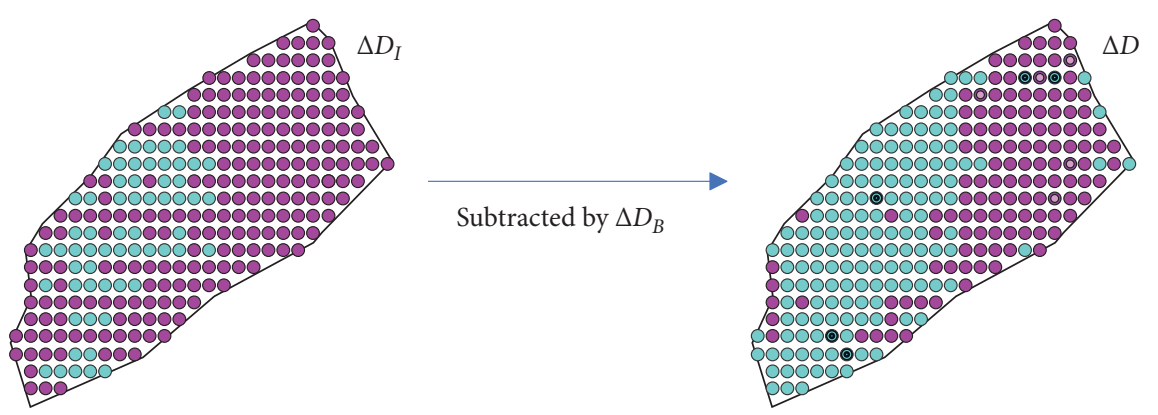

Figure 4: Change of the difference between the pre- and postearthquake DEM after correction. Purple dots represent net gain places and blue dots represent net loss places.

The relation of $\log (A)$ versus $\log (V)$ has an $R^{2}$ value of 0.8739 (Figure 6). Thus, the relation of $V-A$ is

$$
V=0.5901 A^{1.1987 \pm 0.0263} \text {, }
$$

which is largely consistent with those in the previous work (see Table 1).

Combining the result in Figure 6 with the landslide areafrequency relation shown in Figure 1(c), it demonstrates that most coseismic landslides in the study area are within the size range of $10^{4}-10^{5} \mathrm{~m}^{2}$. There are 210 landslides falling in this area range, which account for $66 \%$ of the total number of the landslides in the study area. However, these landslides have a total volume of $0.677 \times 10^{8} \mathrm{~m}^{3}$, which accounts for only $38.4 \%$ of the total landslide volume. This implies that large-scale landslides are the primary contributor to the volume of coseismic landslides and have major influence on the calculation of this parameter. Considering these big slope failures are typically deep-seated, of which the depths are generally greater than the errors in elevations from DEMs, the method using elevation variations to calculate the landslide volume is more suitable for large slope failures, as they can produce surface changes larger than errors of DEMs. 


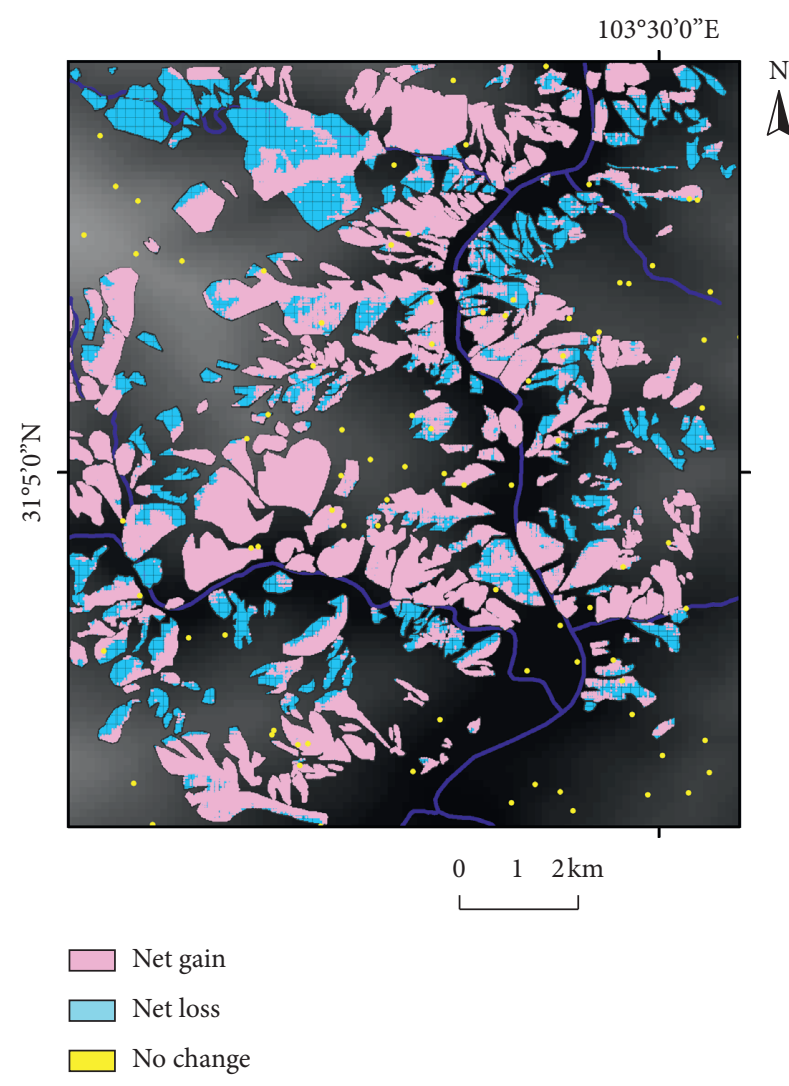

(a)

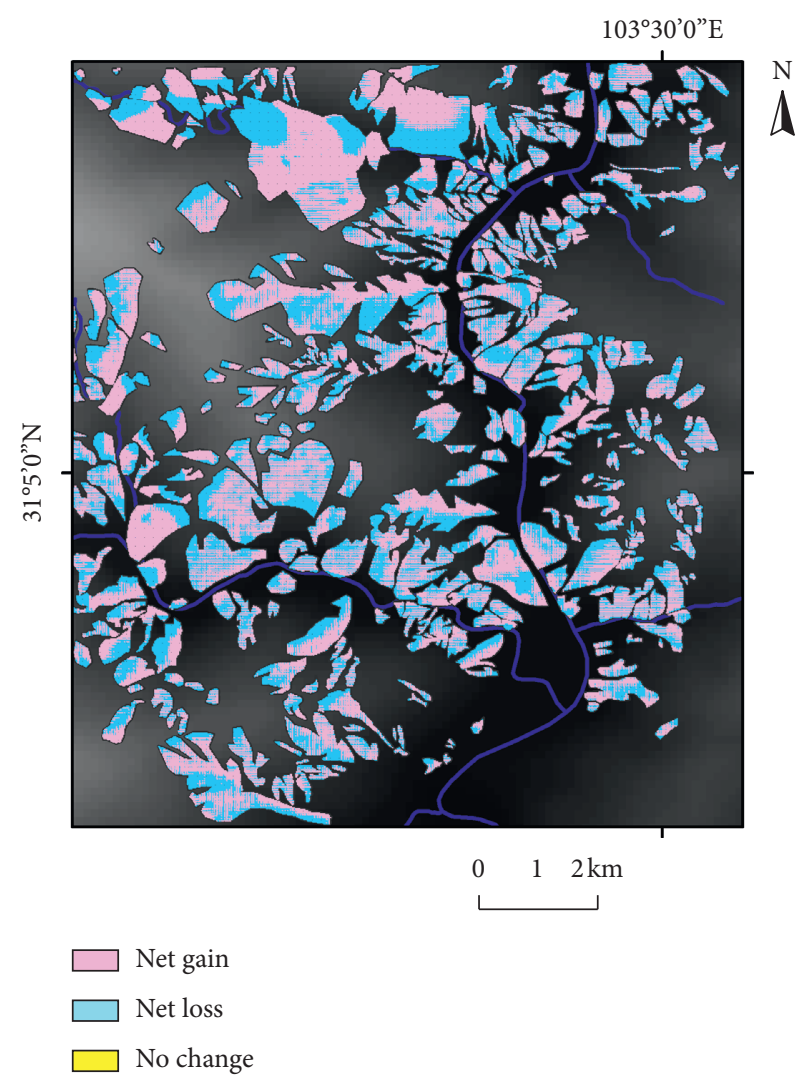

(b)

Figure 5: Difference between the pre- and postearthquake DEMs before the correction (a) and after correction (b) in the study area. Pink dots represent net gain, and blue dots represent net loss.

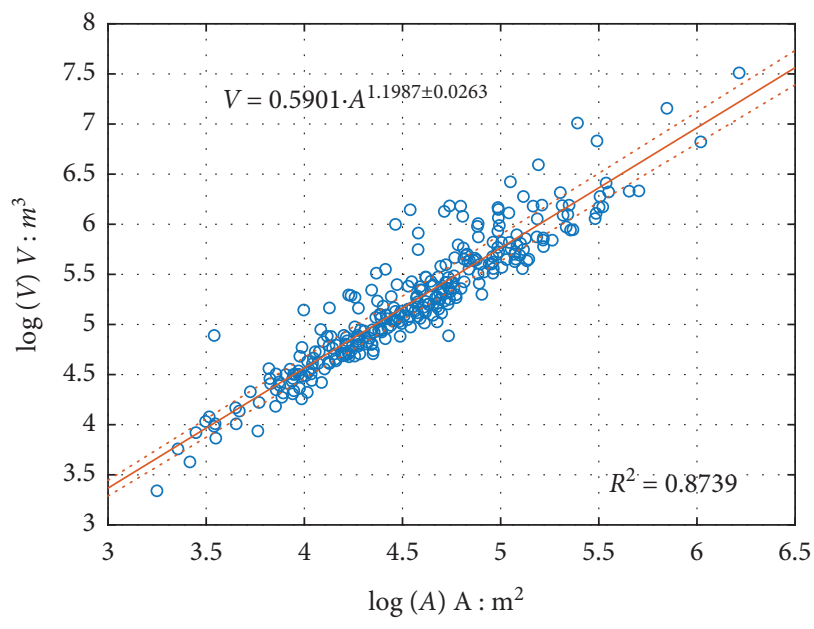

FiguRE 6: Relation between the landslide volume and landslide area in logarithm.

\section{Discussion}

As a comparison, we use the empirical $V$-A formulas with $\alpha$ and $\gamma$ from different studies to estimate the total landslide volume in the study area. Results are displayed in Table 1.
TABle 1: Calculated landslide volumes using $V$ - $A$ relation with different coefficients.

\begin{tabular}{lcccc}
\hline Item & $\alpha$ & $\gamma$ & Landslide volume $\left(\mathrm{m}^{3}\right)$ & References \\
\hline 1 & 0.186 & 1.35 & $2.834 * 10^{8}$ & Larsen et al.[5] \\
2 & 0.074 & 1.45 & $3.985 * 10^{8}$ & Guzztti et al. [13] \\
3 & 1.3147 & 1.2085 & $3.487 * 10^{8}$ & Xu et al. [10] \\
4 & 0.106 & 1.388 & $2.608 * 10^{8}$ & Parker et al. [11] \\
5 & 0.5901 & 1.1987 & $1.388 * 10^{8}$ & This work \\
\hline
\end{tabular}

It can be seen that different $\alpha$ and $\gamma$ values result in a wide range of calculated landslide volumes. Even for the formula derived from this work, the difference exists between volumes obtained from the $V$-A formula $\left(1.388 * 10^{8} \mathrm{~m}^{3}\right.$ in Table 1) and the DEMs method $\left(1.765 \times 10^{8} \mathrm{~m}^{3}\right)$.

In fact, in the conventional relation ${ }_{V}=\alpha_{A}^{\gamma}$, the functions of $\alpha$ and $\gamma$ are analogous to landslide depths. With parameters $A$ and $V$ of landslides, using the various fitting methods to solve for depth is a basic principle. Therefore, the landslide area and quantity are important for obtaining a suitable regression formula. However, due to the subjective mapping by researchers, which defines the existence and/or extent of landslides [7, 8, 29], there exist obvious discrepancies in the quantity of landslides or the landslide boundaries, such as different landslide inventories compiled 
for the Wenchuan earthquake $[7,8,29,30]$. In addition, coseismic landslide occurrence is subject to many factors including local topography, geology, and even local rock features. All these factors will greatly affect the coefficients $\alpha$ and $\gamma$ when applying various fitting methods. For these reasons, it is not surprising that there are different $\alpha$ and $\gamma$ in different studies (Table 1). Some researchers suggested that the existing $V$ - $A$ relations may overestimate the volumes of shallow landslides [18]. As for very large landslides, like the Daguangbao landslide triggered by the 2008 Wenchuan M7.9 earthquake, these relations can result in highly variable estimation values of landslide volumes [10]. Therefore, results of landslide morphometrics derived from various $V-A$ relations are generally not comparable.

Compared to scaling relations derived from a limited number of measurements in traditional methods $[5,6]$, using DEMs is more powerful to develop methods to quantify changes in elevation [18-20]. However, as mentioned previously, the elevation errors are always present in DEM data, and different DEM resolutions or DEM source data can cause errors when they are used for comparative analysis $[10,28]$. It is difficult to have perfect matchable DEM data before and after a major earthquake [10]. Then, how to effectively apply the available DEM seems more important.

This study focuses on the landslide volume calculation, exploring how to eliminate the background errors in DEMs. However, individual landslides existing in areas both classified as net gain and net loss (Figure 3) mean that the background error is not a constant and cannot be generalized over an entire study region. So, it is relatively reasonable to consider the background error of each slope for calculation of the landslide volume. Figure 5(b) shows the changes after eliminating background errors with regard to individual landslides. When compared with Figure 3, it can be noted that both areas of net gain and net loss appear within a delineated landslide.

Unlike previous studies (e.g., $\mathrm{Xu}$ et al.) based on the deposition area of landslides determined by pre- and postearthquake DEM, this work takes the whole landslide (including both source and deposit area) as a target. Then, the principle that, in a landslide, the mass moved from the source area is equal to the mass gained in the deposit area can be applied effectively. This application permits to overlook unattainable data, such as landslide slip surface, clear boundaries between the source and deposit areas, and negate the issue of discrepancies within landslides inventories.

The limits of the method are mainly from the resolution of DEMs, and we do notice that this is still an open question to be addressed. Using pre- and postearthquake DEMs to calculate the landslide volume requires that the elevation difference should be greater than the depth of landslides, which ensures that the precision is sufficient for measuring the landslide volume by subtracting the pre-earthquake DEM from the postearthquake one [18]. This is why, this method is more suitable for large-scale landslides $[20,28]$, although both pre- and postearthquake DEMs inevitably still have elevation errors in this case. Unfortunately, the study

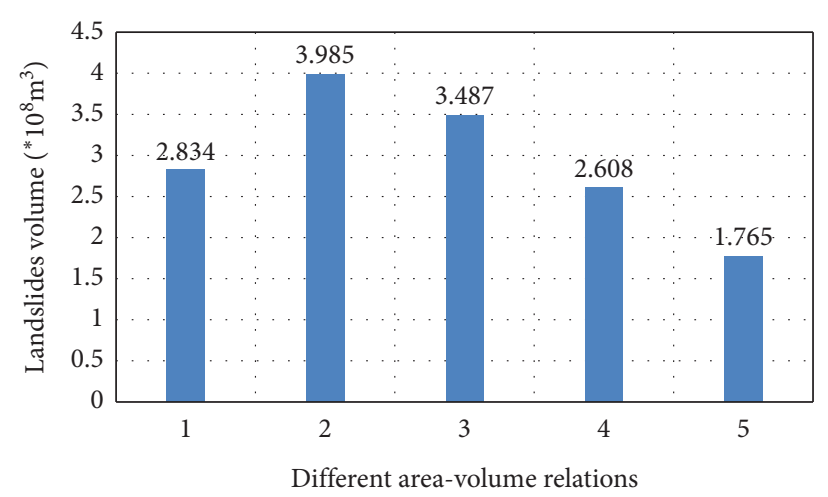

FIgURe 7: Calculated coseismic landslide volumes with values from the different area-volume relations (1: Larsen et al.; 2: Guzztti et al.; 3: Xu et al.; 4: Parker et al.; and 5: this work).

area lacks postearthquake GPS data, so it is difficult to estimate the elevation error. Besides, this method removes the background error based on the difference of changes of the slope volume between the source and deposit areas, while material left at the source area after the landsliding is not taken into consideration because it did not move to the deposit area. Thus, the volume of the whole landslide may be underestimated. Nevertheless, many landslide cases show that only a small part of slope material was left at the source area after strong seismic shaking, so the overlay area has a little effect on the volume calculation for coseismic landslides.

In the case that deposit expansion rates of up to $20 \%$ of landslide masses as observed in some studies [26, 27], the DEM-based method may underestimate the deposit volume because of background error $\left(\Delta D_{B}\right)$, which is subtracted from the deposit area leading to a smaller volume. However, because the background error is evenly distributed through the whole landslide polygon, the impact of the background error $\left(\Delta D_{B}\right)$ on the volume is very limited $(<10 \%)$ compared to the error inherent to the DEM, which is around several meters [18]. In other words, the volume of coseismic landslides calculated by the DEM-based method may represent a minimum value ((Figure 7).

\section{Conclusions}

Calculating the volume of earthquake-triggered landslides is an important but difficult issue. Comparing pre- and postearthquake DEMs permits to calculate the elevation change by landsliding and then calculate the volume of landslides in a chosen area. This work tests this approach based on the data from the Yingxiu area, Sichuan, China, near the epicenter of the $2008 \mathrm{Mw} 7.9$ Wenchuan earthquake, which triggered massive coseismic slope failures. The conclusions of this study are as follows:

(1) To use effectively the DEMs-based method to calculate the landslide volume, it is necessary to eliminate background errors of elevations in individual landslides firstly, which are associated with different sources and resolutions of pre- and 
postearthquake DEMs. With such a preprocessing, the calculated landslide volume may be more reasonable.

(2) Using the DEMs-based method, the total landslide volume in the study area is $1.765 \times 10^{8} \mathrm{~m}^{3}$. Considering the simplification in this approach, the volume of coseismic landslides calculated may represent a minimum value.

(3) By a log-linear regression, a relation between the landslide volume and area for the study area is derived, largely consistent with that in previous work. Combining the frequency-area and volume-area relations in the study area, it is noted that the largescale landslides are the major contributor to the calculated volume. And, the DEMs-based method is more suitable for the calculation of large-scale earthquake-triggered landslides.

\section{Data Availability}

The data used to support the findings of this study are available at http://srtm.csi.cgiar.org/SELECTION/ inputCoord.asp.

\section{Conflicts of Interest}

The authors declare that they have no conflicts of interest.

\section{Acknowledgments}

This work was supported by the National Key Research and Development Program (no. 2017YFC1501004) and Basic Scientific Research Project of Institute of Geology, China Earthquake Administration (no. IGCEA1604).

\section{References}

[1] D. K. Keefer, "The importance of earthquake-induced landslides to long-term slope erosion and slope-failure hazards in seismically active regions," Geomorphology, vol. 10, no. 1-4, pp. 265-284, 1994.

[2] N. Hovius, C. P. Stark, and P. A. Allen, "Sediment flux from a mountain belt derived by landslide mapping," Geology, vol. 25, no. 3, pp. 231-234, 1997.

[3] B. D. Malamud, D. L. Turcotte, F. Guzzetti, and P. Reichenbach, "Landslides, earthquakes, and erosion," Earth and Planetary Science Letters, vol. 229, no. 1-2, pp. 45-59, 2004.

[4] O. Korup, A. L. Densmore, and F. Schlunegger, "The role of landslides in mountain range evolution," Geomorphology, vol. 120, no. 1-2, pp. 77-90, 2010.

[5] I. J. Larsen, D. R. Montgomery, and O. Korup, "Landslide erosion controlled by hillslope material," Nature Geoscience, vol. 3, no. 4, pp. 247-251, 2010.

[6] R. N. Parker, A. L. Densmore, N. J. Rosser et al., "Mass wasting triggered by the 2008 Wenchuan earthquake is greater than orogenic growth," Nature Geoscience, vol. 4, no. 7, pp. 449-452, 2011.

[7] F. C. Dai, C. Xu, X. Yao, L. Xu, X. B. Tu, and Q. M. Gong, "Spatial distribution of landslides triggered by the $2008 \mathrm{Ms} 8.0$
Wenchuan earthquake, China," Journal of Asian Earth Sciences, vol. 40, no. 4, pp. 883-895, 2011.

[8] S. Qi, Q. Xu, B. Zhang, Y. Zhou, H. Lan, and L. Li, "Source characteristics of long runout rock avalanches triggered by the 2008 Wenchuan earthquake, China," Journal of Asian Earth Sciences, vol. 40, no. 4, pp. 896-906, 2011.

[9] C. Xu, X. Xu, X. Yao, and F. Dai, "Three (nearly) complete inventories of landslides triggered by the May 12, 2008 Wenchuan Mw 7.9 earthquake of China and their spatial distribution statistical analysis," Landslides, vol. 11, no. 3, pp. 441-461, 2014.

[10] C. Xu, X. Xu, L. Shen et al., "Optimized volume models of earthquake-triggered landslides," Scientific Reports, vol. 6, no. 1, Article ID 29797, 2016.

[11] S. Zhou, G. Chen, and L. Fang, "Distribution pattern of landslides triggered by the 2014 ludian earthquake of China: implications for regional threshold topography and the seismogenic fault identification," ISPRS International Journal of Geo-Information, vol. 5, no. 4, p. 46, 2016.

[12] D. S. Simonett, "Landslide distribution and earthquakes in the bewani and torricelli mountains, new Guinea," in Landform Studies from Australia and NewGuinea, J. N. Jennings and J. A. Mabbutt, Eds., pp. 64-84, Cambridge University Press, Cambridge, UK, 1967.

[13] F. Guzzetti, F. Ardizzone, M. Cardinali, M. Rossi, and D. Valigi, "Landslide volumes and landslide mobilization rates in Umbria, central Italy," Earth and Planetary Science Letters, vol. 279, no. 3-4, pp. 222-229, 2009.

[14] P. Frattini and G. B. Crosta, "The role of material properties and landscape morphology on landslide size distributions," Earth and Planetary Science Letters, vol. 361, pp. 310-319, 2013.

[15] O. Katz, J. K. Morgan, E. Aharonov, and B. Dugan, “Controls on the size and geometry of landslides: insights from discrete element numerical simulations," Geomorphology, vol. 220, pp. 104-113, 2014.

[16] X.-L. Chen, C.-G. Liu, Z.-F. Chang, and Q. Zhou, “The relationship between the slope angle and the landslide size derived from limit equilibrium simulations," Geomorphology, vol. 253, pp. 547-550, 2016.

[17] L.-j. Su, X.-q. Xu, X.-y. Geng, and S.-q. Liang, “An integrated geophysical approach for investigating hydro-geological characteristics of a debris landslide in the Wenchuan Earthquake Area," Engineering Geology, vol. 219, pp. 52-63, 2017.

[18] Z. Ren, Z. Zhang, F. Dai, J. Yin, and H. Zhang, “Topographic changes due to the 2008 Mw7.9 Wenchuan earthquake as revealed by the differential DEM method," Geomorphology, vol. 217, pp. 122-130, 2014.

[19] M. E. Oskin, J. R. Arrowsmith, A. H. Corona et al., "Near-field deformation from the el mayor-cucapah earthquake revealed by differential LIDAR," Science, vol. 335, no. 6069, pp. 702-705, 2012.

[20] R.-F. Chen, K.-J. Chang, J. Angelier et al., “Topographical changes revealed by high-resolution airborne LiDAR data: the 1999 Tsaoling landslide induced by the Chi-Chi earthquake," Engineering Geology, vol. 88, no. 3-4, pp. 160-172, 2006.

[21] C. Xu, X. W. Xu, T. Gorum, C. J. van Westen, and X. M. Fan, "Did the 2008 Wenchuan earthquake lead to a net volume loss?," in Landslide Science for a Safer Geoenvironment, K. Sassa, Ed., vol. 3, pp. 191-196, Springer International Publishing, Cham, Switzerland, 2014.

[22] W. Yang, W. Qi, M. Wang, J. Zhang, and Y. Zhang, "Spatial and temporal analyses of post-seismic landslide changes near 
the epicentre of the Wenchuan earthquake," Geomorphology, vol. 276, pp. 8-15, 2017.

[23] P.-Z. Zhang, X.-z. Wen, Z.-K. Shen, and J.-h. Chen, "Oblique, high-angle, listric-reverse faulting and associated development of strain: the wenchuan earthquake of may 12, 2008, sichuan, China," Annual Review of Earth and Planetary Sciences, vol. 38, no. 1, pp. 353-382, 2010.

[24] X. Fan, C. J. van Westen, Q. Xu, T. Gorum, and F. Dai, "Analysis of landslide dams induced by the 2008 Wenchuan earthquake," Journal of Asian Earth Sciences, vol. 57, pp. 25-37, 2012.

[25] Y. Tian, C. Xu, S. Ma, X. Xu, S. Wang, and H. Zhang, "Inventory and spatial distribution of landslides triggered by the 8th August 2017 Mw 6.5 Jiuzhaigou earthquake, China," Journal of Earth Science, vol. 30, no. 1, pp. 206-217, 2019.

[26] O. Hungr and S. G. Evans, "Entrainment of debris in rock avalanches: an analysis of a long run-out mechanism," Geological Society of America Bulletin, vol. 116, no. 9, pp. 1240-1252, 2004.

[27] M. Geertsema, O. Hungr, J. W. Schwab, and S. G. Evans, "A large rockslide-debris avalanche in cohesive soil at Pink Mountain, northeastern British Columbia, Canada," Engineering Geology, vol. 83, no. 1-3, pp. 64-75, 2006.

[28] F. Gallo and J. Lavé, "Evolution of a large landslide in the High Himalaya of central Nepal during the last half-century," Geomorphology, vol. 223, pp. 20-32, 2014.

[29] Y. Yin, F. Wang, and P. Sun, "Landslide hazards triggered by the 2008 Wenchuan earthquake, Sichuan, China," Landslides, vol. 6, no. 2, pp. 139-152, 2009.

[30] R. Q. Huang and W. L. Li, "A study on the development and distribution rules of geohazards triggered by "5.12" Wenchuan Earthquake," The Chinese Journal of Mechanical Engineering, vol. 27, pp. 2585-2592, 2008, in Chinese. 